\title{
Direct and Distributed Strain Measurements Inside a Shotcrete Lining: Concept and Realisation
}

\author{
Lukas Wagner $^{1}$ (D) Alexander Kluckner ${ }^{1} \cdot$ Christoph Martin Monsberger ${ }^{2} \cdot$ Petra Wolf $^{3} \cdot$ Karoline Prall $^{4}$. \\ Wulf Schubert ${ }^{1} \cdot$ Werner Lienhart ${ }^{2}$
}

Received: 2 November 2018 / Accepted: 18 July 2019 / Published online: 12 August 2019

(C) The Author(s) 2019

\begin{abstract}
This paper introduces the successful implementation of a fibre-optic sensing system for direct and distributed strain measurement within the shotcrete lining of a conventional tunnel drive. The shotcrete lining of the top-heading and the invert are equipped with two layers (rock side and cavity side) of fibre-optic sensing cables installed in circumferential and longitudinal direction. All cables are measured autonomously for several weeks to capture the strain evolution inside the lining from the day of the construction to a posterior, well-hardened state. An additional follow-up measurement is conducted 2 months afterwards. The measurements enable an assessment of the strain distribution inside the lining with a spatial resolution in the range of some centimetres and a measurement resolution of up to $1 \mu \mathrm{m} / \mathrm{m}$. Besides the conventional monitoring targets used for displacement recordings, measurement equipment like strain gages and pressure cells are also installed in the crosssection under investigation. Back-calculated strain from absolute displacements and the readings from the strain gages show good agreement with the results of the conducted fibre-optic measurements and verify the suitability of the used system.
\end{abstract}

Keywords Distributed fibre-optic sensing $\cdot$ Strain measurement $\cdot$ Shotcrete lining $\cdot$ Tunnelling

Lukas Wagner

luk.wagner@gmx.at

Alexander Kluckner

kluckner@tugraz.at

Christoph Martin Monsberger

christoph.monsberger@tugraz.at

Petra Wolf

petra.wolf@oebb.at

Karoline Prall

kprall@ambergengineering.com

Wulf Schubert

schubert@tugraz.at

Werner Lienhart

werner.lienhart@tugraz.at

1 Institute of Rock Mechanics and Tunnelling, Graz University of Technology, Rechbauerstraße 12, 8010 Graz, Austria

2 Institute of Engineering Geodesy and Measurement Systems, Graz University of Technology, Steyrergasse 30/II, 8010 Graz, Austria

3 ÖBB-Infrastruktur AG, Griesgasse 11/1, 8020 Graz, Austria

4 Amberg Engineering AG, Grabenweg 68, 6020 Innsbruck, Austria

\section{Introduction}

In tunnelling, engineers at construction sites have to assess the system stability every day. Geotechnical measurements and observations are usually taken to decide whether the current excavation and support concept satisfies the needs or requires modifications.

Accordingly, the knowledge of the degree of utilisation of the support is of great interest. Systems to directly measure the support utilisation or physical quantities related to the utilisation are not commonly used in conventional tunnelling as of today. In general, the degree of utilisation of the support is often approximated (e.g. utilisation of the shotcrete lining calculated from displacements of monitoring points) or evaluated visually (e.g. deformation or failure of anchor plates).

These circumstances raise the questions of the real-time strain and therefore stress distribution as well as of the stress history inside the outer (shotcrete) lining of a tunnel. Conventional monitoring techniques enable only the backcalculation of strain within the shotcrete lining using displacement data from monitoring targets. Strain gages can be installed at defined positions along the circumference of the 
tunnel to locally record the strain development. Everything in between has to be interpolated with a natural degree of uncertainty.

To bypass these described deficiencies of state-of-the-art strain monitoring techniques, the presented research focuses on the direct continuous measurement of strain within the shotcrete lining at its full circumference.

Distributed fibre-optic sensing (DFOS) is found to feature the required capabilities for this type of monitoring application. In the following, the measurement system with its individual components is introduced (Sect. 2). Next, the onsite installation to verify the durability of the system with respect to various mechanical and thermal influences during the installation process is described (Sect. 3). Furthermore, the results and findings are presented (Sect. 4) as well as compared to the results of conventional monitoring techniques (Sect. 5). Finally, a concluding outlook (Sect. 6) is given. Utilizing the DFOS system presented in this paper and with a constitutive relation appropriately describing the load- and time-dependent deformation behaviour of shotcrete, it should be possible to establish a complete picture of the stress state within the shotcrete lining.

\section{Measurement System}

As part of monitoring of structural properties of buildings and other objects in civil engineering, distributed fibre-optic sensing systems represent a significant extension to the existing and currently used sensing technology.

As the entire fibre is the sensor, DFOS provide continuous measurements with likewise very small size and low weight of the sensing cable itself. The cable management is relatively easy compared to conventional systems and it can be built in directly or attached to almost any object. In addition, the system is insensitive to electromagnetic interference and can also operate under extreme temperature conditions. The sensor requires no external power supply (measurement with light) and can be hundreds of meters away from the actual measurement instrument (data logger) (Döring et al. 2016).

In geotechnics, this technology is used more frequently for monitoring purposes. For instance, a DFOS system was implemented in a reinforced earth structure as part of monitoring slope stabilisation measures (Schuller et al. 2014; Moser et al. 2016). In another application, DFOS sensors were used to monitor the distributed strain behaviour along various geotechnical elements, see e.g. Monsberger et al. (2016) or Monsberger et al. (2017).

In conventional tunnelling, distributed fibre-optic sensors for strain monitoring were already successfully installed in a shotcrete lining during the excavation of cross-passages at the Crossrail project in London (de Battista et al. 2015).
Moreover, this technique was used to measure deformations within tunnel segments during the ring building process at continuous tunnelling (Gehwolf et al. 2016; Monsberger and Lienhart 2017).

\subsection{Optical Backscatter Reflectometer (OBR)}

Rayleigh scattering is one of the main reasons for the intensity loss of signal in optical fibres and is caused by variations of the refraction index of the glass fibre core. The basic working principal of the distributed system is based on the scattering of an injected light pulse on natural inhomogeneities of the glass (Rayleigh backscatter) along the fibre core.

The reflected light carries information about the local strain and temperature at a certain point in time. If the fibre is exposed to external influences during two measurements, like a change in strain or temperature, a relative frequency shift arises in the locally reflected frequency spectrum. This change in frequency is directly proportional to the local change in strain or temperature. Further information about the sensing principle may be found in Kreger et al. (2006).

For the project presented in this paper an optical backscatter reflectometer (OBR) from Luna Innovations Inc. (USA) is used. The instrument operates on the basis of the Rayleigh scattering and can capture strain and temperature changes at a very high accuracy of up to $1 \mu \mathrm{m} / \mathrm{m}$ and $0.1^{\circ} \mathrm{C}$ with a spatial resolution within the centimetre range (Luna Innovations 2014).

Using the OBR technique, only relative changes in strain and temperature can be recorded. Thus, all measurements are referenced to a zero measurement conducted at the beginning. To determine, for example, absolute temperature values, the initial values have to be known and added as a static offset to all measurements.

\subsection{Fibre-Optic Sensing Cables}

Due to the harsh environmental conditions inside a tunnel, the fibre-optic sensing fibres must be protected during the installation to ensure the operative usage at the monitoring procedure. Also a proper compound between the fibre and its surrounding protective layers as well as a good bond between the cable itself and the concrete is necessary to get an unbiased transfer of the stress, and therefore strain, inside the concrete to the sensitive glass fibre core.

In the presented monitoring application, the special armoured fibre-optic sensing cable BRUsens strain V3 of Brugg Cables AG, now Solifos AG (Switzerland), is used (Fig. 1). The cable has an outer diameter of $7.2 \mathrm{~mm}$, weighs $75 \mathrm{~kg} / \mathrm{km}$ and comprises a single optical fibre embedded in a metal tube which is hermetically sealed in a first protective plastic layer. The special steel armouring and a secondary polyamide outer sheath with a structured surface for 


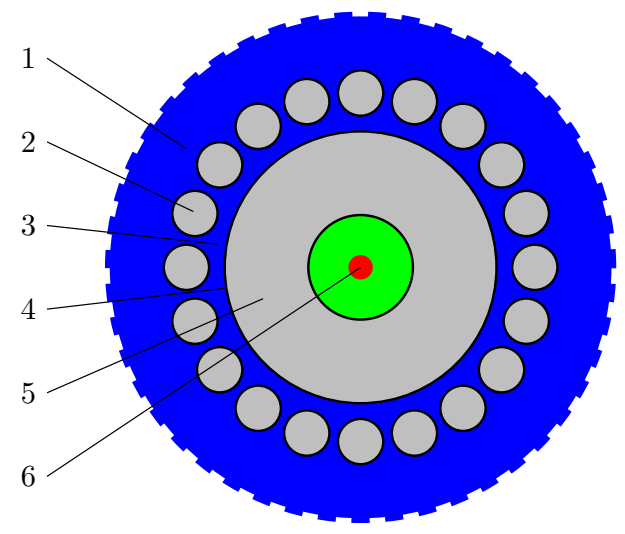

Fig. 1 Schematic cross-section of BRUsens strain V3 Ø $7.2 \mathrm{~mm}$ (Brugg Kabel 2012) with: 1 polyamide outer sheath, with structured surface, 2 special grade galvanized steel armouring, 3 plastic protection layer with interlocking system, 4 metal tube SS316L for protection and hermetic seal, 5 multi-layer buffer and strain transfer layer with interlocking system, 6 special strain optical single mode fibre

maximum bonding properties makes this cable particularly durable. It can be operated at temperatures ranging from -30 to $+70{ }^{\circ} \mathrm{C}$ (Brugg Kabel 2012).

External temperature not only affects but also alters the measured strain arising from the external loading situation. Therefore, an additional sensing fibre which is not influenced by mechanically induced strain must be installed in practical applications to compensate temperature effects. The pure strain component due to mechanical loading (i.e. stress transfer from the shotcrete to the glass fibre) can then be calculated by subtracting the temperature component from the measured strain (called temperature compensation).

The fibre-optic sensing cable BRUsens strain V3 is used both for strain measurement (directly embedded in the shotcrete) and for temperature compensation (loosely placed in a polyethylene (PE) tube, Ø $25 \mathrm{~mm}$, which is then embedded in the shotcrete). Alternately, a special temperature sensing cable could be used [for details see e.g. Henzinger et al. (2018)]. The applicability of different fibre-optic sensing cable types has been investigated within a pre-test on a simple sprayed concrete slab [for details see Wagner (2017)].

\section{Installation at Site}

The test location is situated at the Semmering Base Tunnel project in Austria. The shotcrete lining of the entire crosssection (top-heading and invert) at the monitoring section (MS) at chainage $1439 \mathrm{~m}$ of track 1 at the construction lot SBT 1.1 was equipped with several fibre-optic sensing cables. This cross-section is located in the core zone of the Eichberg fault system (heavily fractured; unconfined compressive strength of fault rocks $<5 \mathrm{MPa}$ ) with an overburden of approx. $135 \mathrm{~m}$ [for more details see Wagner (2017)]. The tunnel section was driven conventionally with the cross-section divided into top-heading (round length $1 \mathrm{~m}$ ) and invert (round length $2 \mathrm{~m}$ ).

On March 14th, 2017, the designed fibre-optic measurement system was installed at the top-heading and 5 days later on March 19th, 2017, at the invert. The continuous measurement started as soon as the installation process of the DFOS system was completed and was carried out for 31 days after the implementation at the invert until April 19th, 2017. After that time, no major displacements and hence no significant strain changes in the lining were expected.

However, the measurement concept was designed in a way to allow a reconnection of the OBR at any time in the future to conduct additional measurements if needed (as long as the fibre-optic sensing cables remain intact).

\subsection{Fibre-Optic Instrumentation}

The fibre-optic sensing cables were installed in circumferential direction (perpendicular to the tunnel axis) as well as in loops (alternately parallel and perpendicular to the tunnel axis) to record strain in longitudinal direction, too.

The first or rock side layer of the fibre-optic sensing cable in longitudinal direction was installed over one round length with a total of seven loops at the top-heading and three loops at the invert (Fig. 2a). The second or cavity side layer was implemented in the same way as the first layer, but with a supplementary cable which stretches over two round lengths (Fig. 2b).

The fibre-optic sensing cables for temperature compensation within the PE-tube were installed at both layers only in circumferential direction to save installation time. It was assumed that the thermal influence is equivalent in longitudinal and circumferential direction.

All fibre-optic sensing cables were mounted on the respective layers of wire mesh by the workers on site using cable ties. After the individual installations and before the application of shotcrete, measurement checks were performed to ensure the full functionality of the fibre-optic sensing cables. The entire installation process took about $1 \mathrm{~h}$ for the rock side layer and $1 \mathrm{~h} 50 \mathrm{~min}$ for the cavity side layer at the top-heading. At the invert it took about $2 \mathrm{~h}$ $20 \mathrm{~min}$ to install the fibre-optic sensing cables at the rock side layer and $1 \mathrm{~h} 30 \mathrm{~min}$ at the cavity side layer. During the installation of the latter a cable break probably occurred close to the connection box so that generally no data could be recorded for this layer.

The interrogation unit was set up in a specially built metal instrument box mounted approximately $60 \mathrm{~m}$ behind the tunnel face at the left tunnel wall to protect it for the duration of the continuous measurement. It was connected via a supply cable with a second metal box (connection box) in the left 


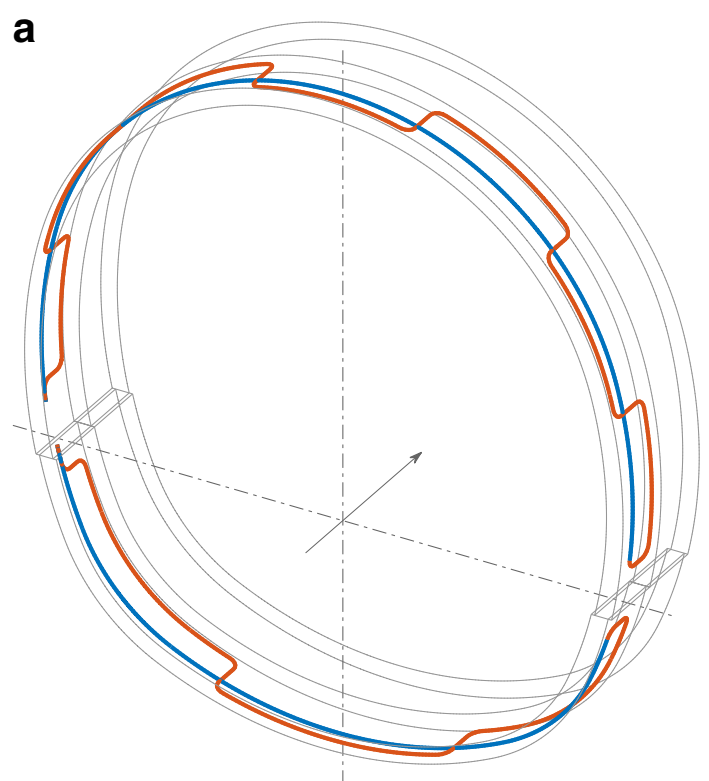

b

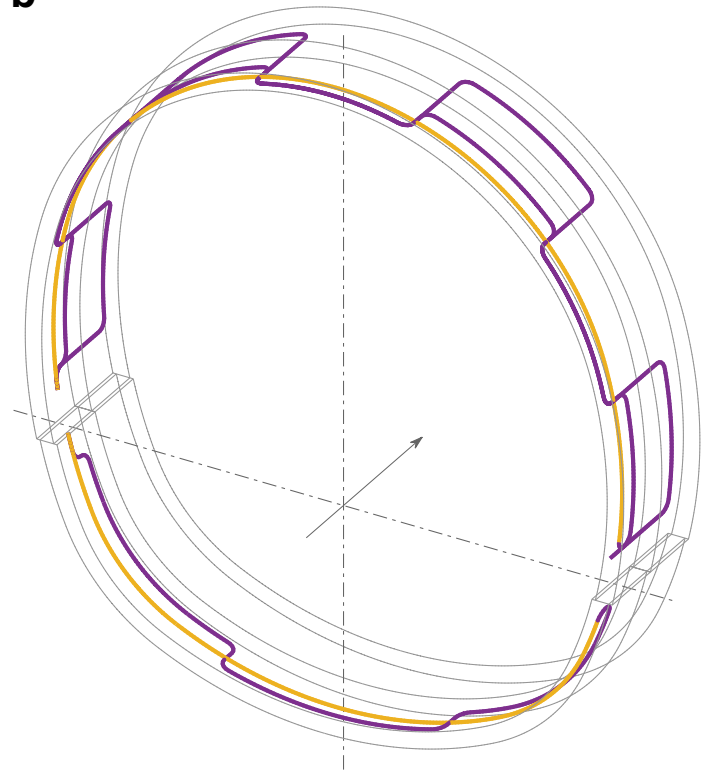

Fig. 2 Schematic sketch of the fibre-optic measurement system setup. a position of the first layer (rock side) of fibre-optic sensing cables. b position of the second layer (cavity side) of fibre-optic sensing cables

side wall which houses the connections between the supply cable and the fibre-optic cables at the monitoring section (see Fig. 3). For protection the supply cable was also placed inside a plastic tube and guided alongside the left tunnel wall.

\subsection{Additional Measurement Equipment}

To evaluate the DFOS results, in addition to five bi-reflex targets for standard geodetic total station measurements the
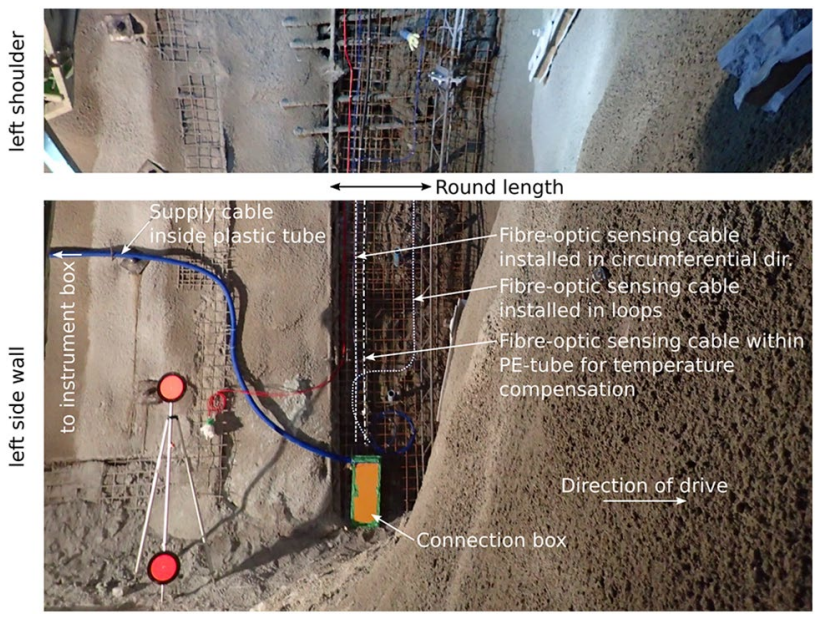

Fig. 3 Measurement setup with the connection box installed at the MS at chainage $1439 \mathrm{~m}$

following measurement equipment was installed at the crosssection under investigation:

- Vibrating wire strain gages mounted tangentially at both layers of wire mesh (12 in total, 6 at the top-heading, 6 at the invert).

- Pressure cells mounted tangentially and radially between the two layers of wire mesh (12 in total, 6 at the topheading, 6 at the invert, 3 in each direction).

\section{Results}

The recorded measurements are always relative changes in strain with respect to a prior carried out reference measurement (=zero measurement) conducted for every line of installed fibre-optic sensing cables separately after the initial application of shotcrete at the respective layer.

All following results are displayed as changes in strain $(\Delta \varepsilon)$ normalised to the distance of $1 \mathrm{~m}(1 \mathrm{~mm} / \mathrm{m}=1000 \mu \mathrm{m} /$ $\mathrm{m}=0.1 \%=1 \%$ ) where a positive value indicates tension and a negative value compression along the fibre-optic sensing cable. The results are already temperature compensated (see Sect. 2.2). Readings are taken at minute intervals. A spatial resolution of $2 \mathrm{~cm}$ is set at the instrument for all conducted measurements.

If blanks are present in the data, either the respective fibre-optic sensing cable is not measured yet, or the data at that point contains serious outliers (e.g. heavy vibrations of the cable during the spraying of shotcrete) and is therefore eliminated from the series. Occasionally, the system is interrupted over a short period due to system errors or power outages resulting in data loss. 
Fig. 4 Evolution of changes in strain of the fibre-optic sensing cables in circumferential direction during the continuous monitoring period at MP1 (crown). Positive: tension; negative: compression

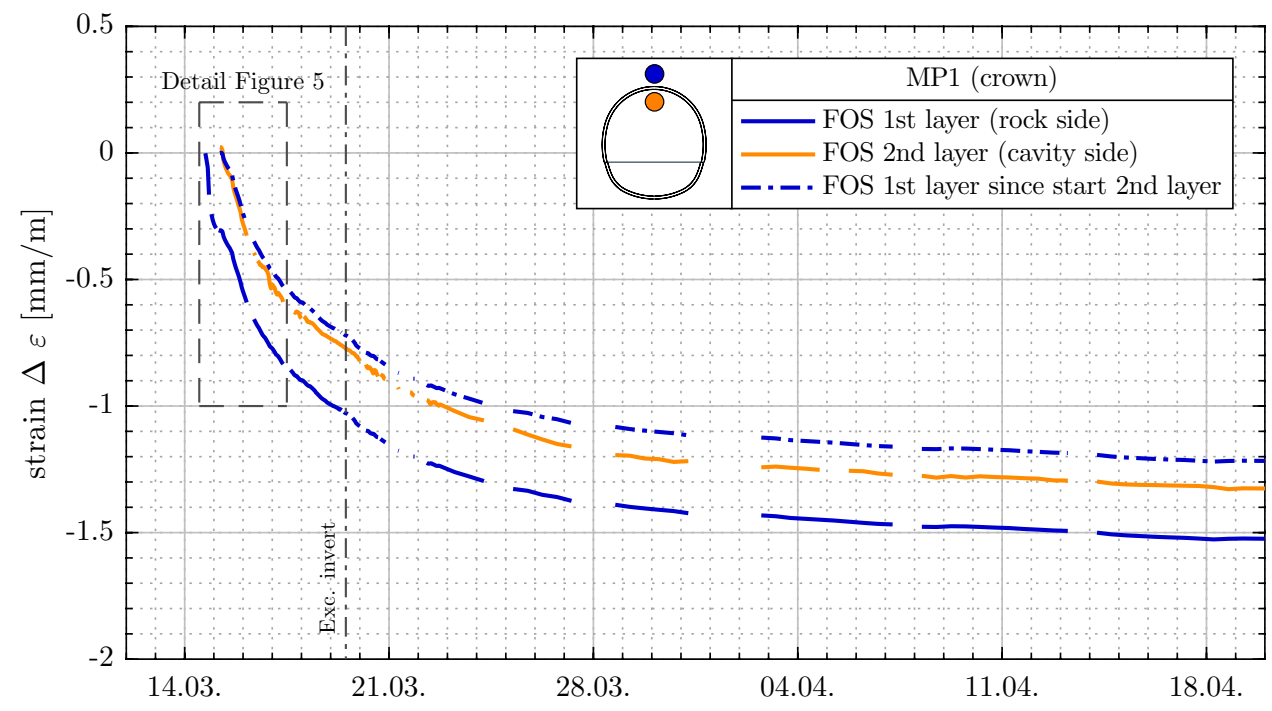

During the monitoring period, temperature deviations to the zero measurement up to $20 \mathrm{~K}$ were observed because of the curing of the shotcrete (i.e. generation of hydration heat first, then cooling) and the continued working process inside the tunnel (e.g. exhaust-gas heat of excavators). In case of neglecting the temperature compensation described above, the temperature deviations would cause errors in strain of more than $0.1 \mathrm{~mm} / \mathrm{m}$, which shows that a reliable temperature compensation is crucial to calculate correct and effective strain values.

\subsection{Evolution of Strain for Single Points}

The diagram in Fig. 4 illustrates the evolution of changes in strain at the crown monitoring point (MP) for the fibre-optic sensing cables in circumferential direction plotted over time. The dash-dotted line shows the data of the rock side layer since the zero measurement of the second cavity side layer to highlight the development of the changes in strain with the completion of the lining.

The maximum gradient of the changes in strain can be observed in the first days after excavation. The changes decrease with time and converge towards a final strain level of approximately $1.3 \mathrm{~mm} / \mathrm{m}$. This development conforms with the displacement development of geodetic monitoring targets as the distance of the tunnel face increases. Strain at both layers develop nearly parallel, leading to the conclusion that almost no bending moments act at this point. The subsequent excavation of the invert from March 18th to March 20th, 2017, has hardly any observable influence on the strain level at the crown.

A follow-up measurement was conducted on June 14th, 2017, about 2 months after the continuous monitoring period, which shows additional changes in strain within the lining of up to $0.1 \mathrm{~mm} / \mathrm{m}$. This leads to the conclusion that the stress redistribution in the rock mass might still be in progress. The results are consistent with the boundary conditions at hand as this monitoring section is situated within the core of a fault zone comprising fault material prone to long-term deformations (Schubert and Schubert 1993).

To observe the timespan with the highest increments of changes in strain, Fig. 5 displays changes in strain in the first 2 days after installation at the crown where the increments are highest. The graph also includes the construction sequence for the top-heading.

It can be seen that the steep increase of changes in strain in the first layer is caused by the excavation of the next round (to chainage $1440 \mathrm{~m}$ ). As soon as the excavation of this particular round is finished and with the application of the second layer of shotcrete (including the installation of the second layer of fibre-optic sensing cables) for both rounds in one working step beginning on March 15th, 2017, 4:00 a.m., the changes in strain decreases significantly. The strain remains at a level of approx. $0.3 \mathrm{~mm} / \mathrm{m}$ before it increases again with the continuation of the top-heading advance.

The excavation of the invert has a major influence on the strain development in the lining of the top-heading. Especially the first layer of fibre-optic sensing cables at the side walls of the top-heading (points closest to the invert) show a notable decrease of compression around the time of the invert construction. As depicted in Fig. 6 for the point at the right side wall (MP5), this decrease starts about four rounds $(\sim 8 \mathrm{~m})$ before the monitoring section and stops (respectively continues to increase again) as soon as the invert is installed (ring closure).

In contrast, the second layer shows an increase in the gradient of the changes in strain four rounds before the invert is excavated at MS-1439.

This behaviour suggests that the excavation of the invert reduces compressional strain - and therefore compressive 
Fig. 5 Changes in strain in the first two days after installation at MP1 (crown) including the advance of the top-heading. Positive: tension; negative: compression
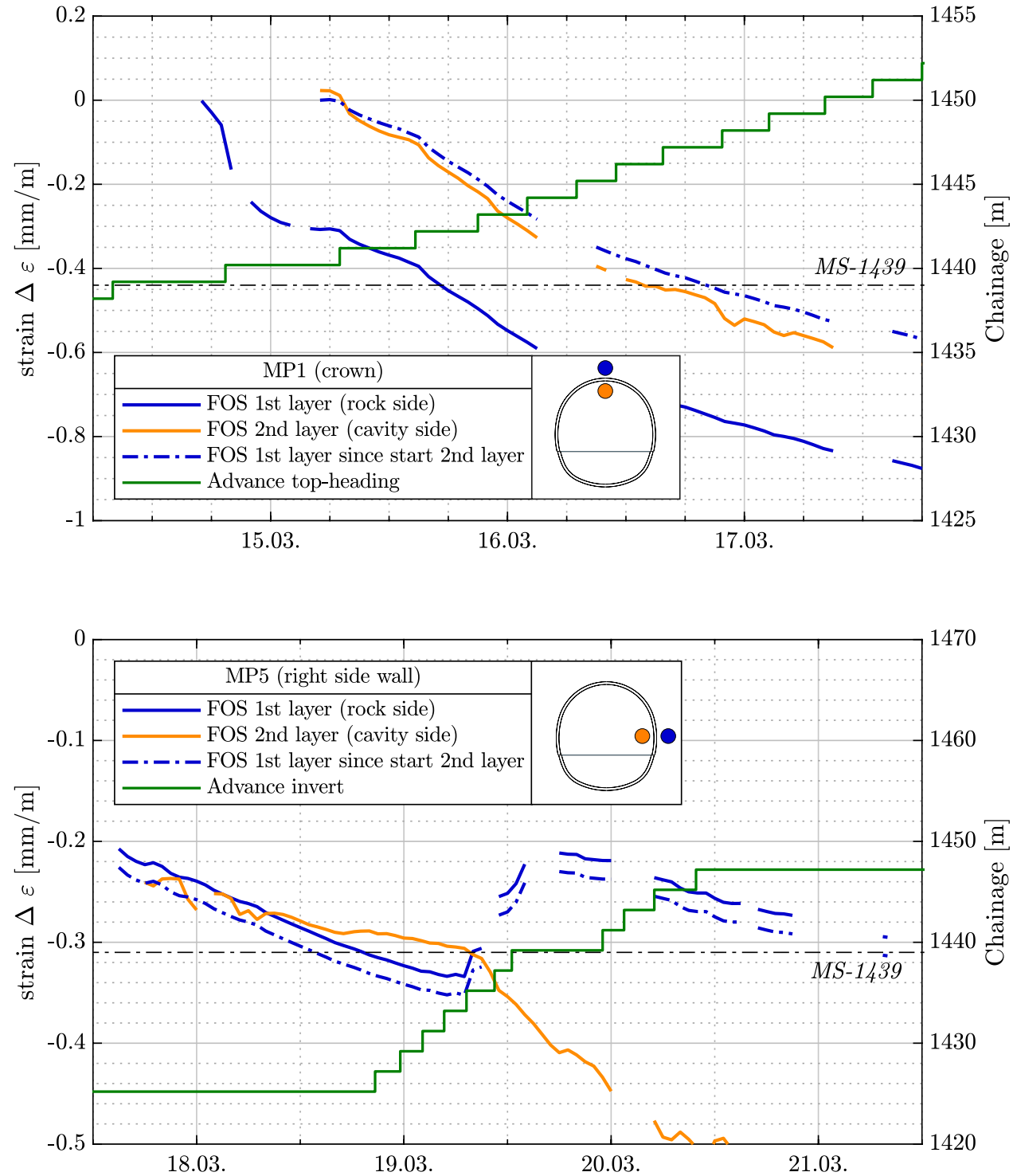

Fig. 6 Changes in strain at MP5 (right side wall) at the time of invert excavation including the advance of the invert. Positive: tension; negative: compression stress - at the rock side layer of shotcrete and simultaneously increases compression at the cavity side part of the lining at the top-heading side walls.

As a consequence of the observed strain difference of the rock and cavity side part of the lining, it might be the case that there a negative bending moment occurs within the lining as a result of the rock deformations. The top-heading foots move slightly horizontally towards the cavity (and maybe even upwards) shortly before the excavation of the invert at MS-1439. This behaviour can also be observed in the displacement vector plots of the convergence recorded with the 3D monitoring targets.

As fibre-optic sensing cables have been installed not only in circumferential direction but also in loops (see Fig. 2), cable parts aligned parallel to the direction of the drive provide information on the strain development within the shotcrete lining in longitudinal direction. The diagram in Fig. 7 shows the evolution of changes in strain in longitudinal direction at selected points (see Fig. 7, top). The changes in strain within the first 2 days are probably dominated by the excavation of the top-heading from chainage $1439 \mathrm{~m}$ to chainage $1448 \mathrm{~m}$ and by time-dependent stress redistributions. From March 18th, 2017, to March 20th, 2017 , the heading of the invert passes the measuring section at chainage $1439 \mathrm{~m}$ and causes the strain of shotcrete fractions close to the invert (i.e. A and E) to change. Note that the amount of changes in strain in longitudinal direction (up to approx. $-1.2 \mathrm{~mm} / \mathrm{m}$ ) is in the same range as in circumferential direction (see Fig. 4). The reason the shotcrete fractions of the first, rock side layer at the locations D and $\mathrm{E}$ get elongated (positive value) and all other shotcrete fractions get compressed (negative value) is unknown. 
Fig. 7 Top: developed top view of the fibre-optic sensing cables installed in loops at the rock side (RS) and at the cavity side (CS; installed over two round lengths) shotcrete layer; from cable parts aligned in longitudinal direction and which are close either to the rock side or to the cavity side cables, respectively, single points (marked with circles) are selected for the comparison of strain at the rock side and at the cavity side (e.g. point $\mathrm{A}$ at RS and point A at CS). Bottom: evolution of changes in strain of the selected points during the continuous monitoring period. Positive: tension; negative: compression
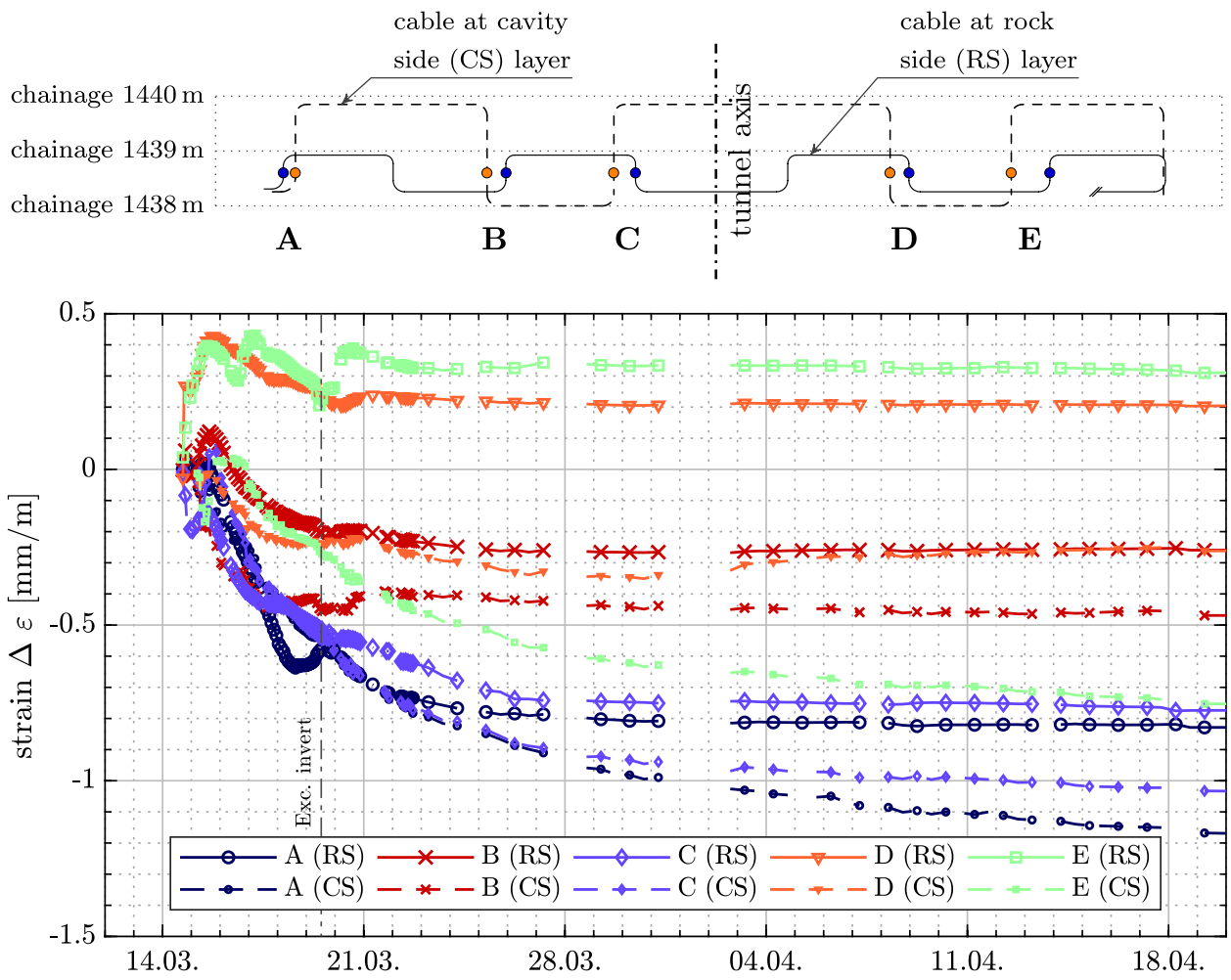

\subsection{Cross-Sectional Distribution of Strain}

In contrast to conventional, point-wise sensing techniques, DFOS systems provide distributed measurements along the entire sensing cable. Therefore, the load distribution can be interpreted along the complete cross-section. Figure 8 shows the recorded cross-sectional distribution of the changes in strain for the individual layers of fibre-optic sensing cables at a specific point in time at the top-heading. The changes in strain with respect to the reference measurement are plotted orthogonal to the tunnel perimeter.

At the rock side layer (Fig. 8a), compression peaks develop at the crown and at both shoulders of the tunnel. The top-heading side walls and footings show slight tensile strain rather than compression. The second layer of shotcrete (Fig. 8c) shows a lower level of strain due to the later application of shotcrete and the later start of the measurement (about $12 \mathrm{~h}$ after the excavation of the top-heading round).

For the first layer an increase in compressive strain at the entire circumference of the top-heading is observable $30 \mathrm{~h}$ later (Fig. 8b). The major peaks are located again at the shoulders and the crown. The later measurement of the second layer (Fig. 8d) shows a larger incremental increase in strain in contrast to the rock side layer. The strain growth is distributed more evenly around the whole circumference of the top-heading with less particular peaks. However, the left side wall gets less stressed compared to the right side wall probably due to the anisotropic rock mass behaviour as the orientation of the dominating foliation of the surrounding rock mass strikes the tunnel axis from the left to the right and steeply dips against the direction of the drive at this chainage.

As described in Sect. 3.1, at the invert only results of the rock side layer can be presented. It can be seen that right after the installation (Fig. 9a) a compression peak starts to develop at the invert point. $24 \mathrm{~h}$ later (Fig. 9b) this peak has further increased and a slight tensional region has developed at the right bench area. At the top-heading, nearly all prominent peaks disappear with the rock mass approaching its final level of deformation.

The cause for the prominent peak at the centre of the invert might be the fact that for the installation of the pressure cell close to the fibre-optic sensing cable a considerable part of the wire mesh had to be removed leading to a lower reinforcement ratio. Due to the lower overall stiffness-especially at the beginning when the shotcrete's stiffness has not fully developed yet-the lining gets more compressed. However, none of the conventional sensors (i.e. strain gages, pressure cells) installed close to the invert point recorded a similar behaviour. Such conclusions might be valid for other remaining peaks at the topheading and the invert but cannot be verified. 
Fig. 8 Circumferential distribution of changes in strain of first and second layer at the early stages after support installation at the top-heading. a First layer $18 \mathrm{~h}$ after applying shotcrete. b First layer $48 \mathrm{~h}$ after applying shotcrete. c Second layer $6 \mathrm{~h}$ after applying shotcrete. $\mathbf{d}$ Second layer $36 \mathrm{~h}$ after applying shotcrete.
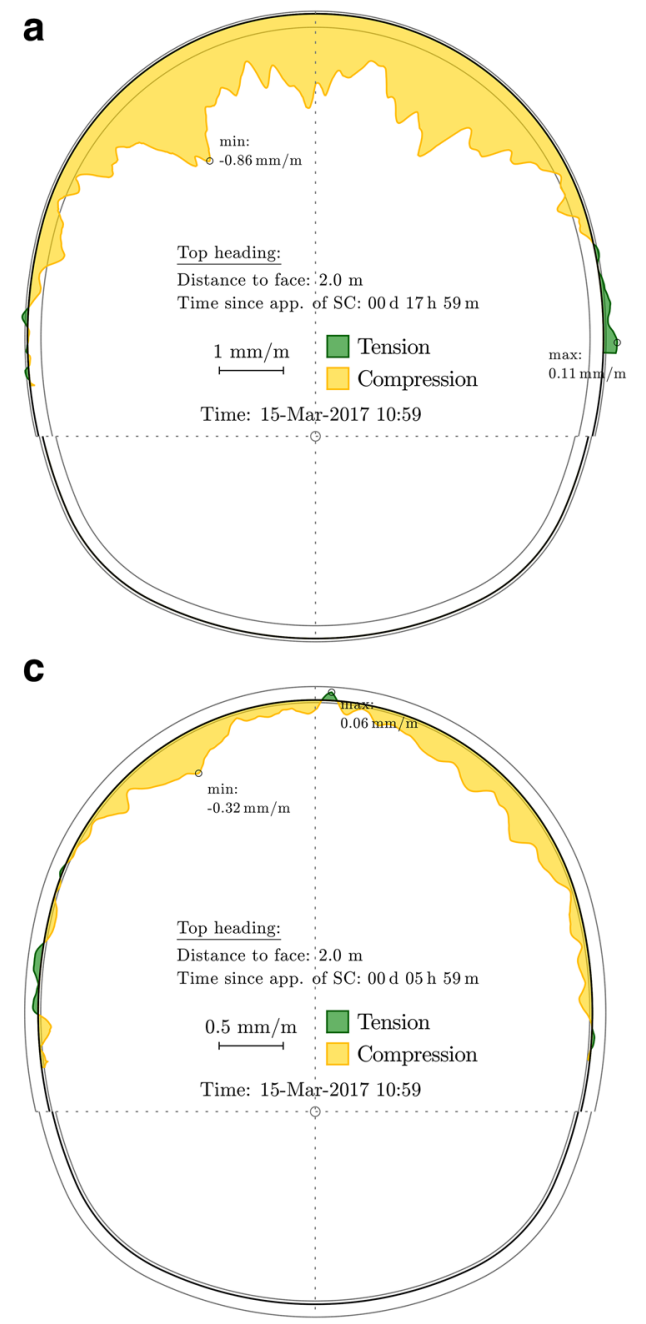

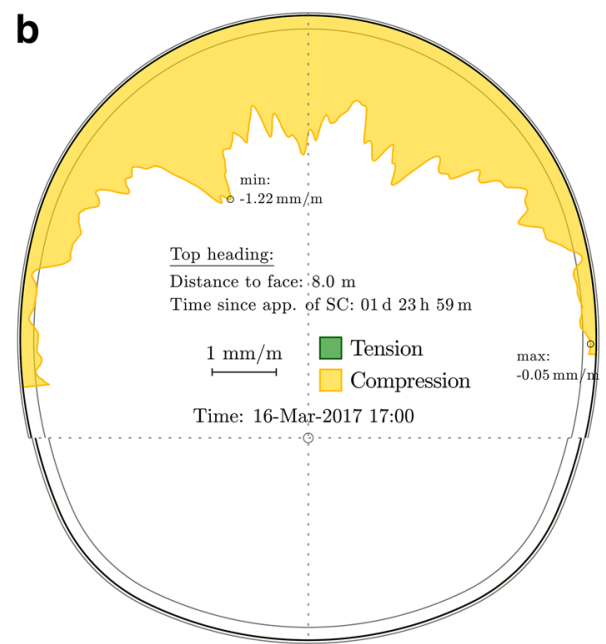

d

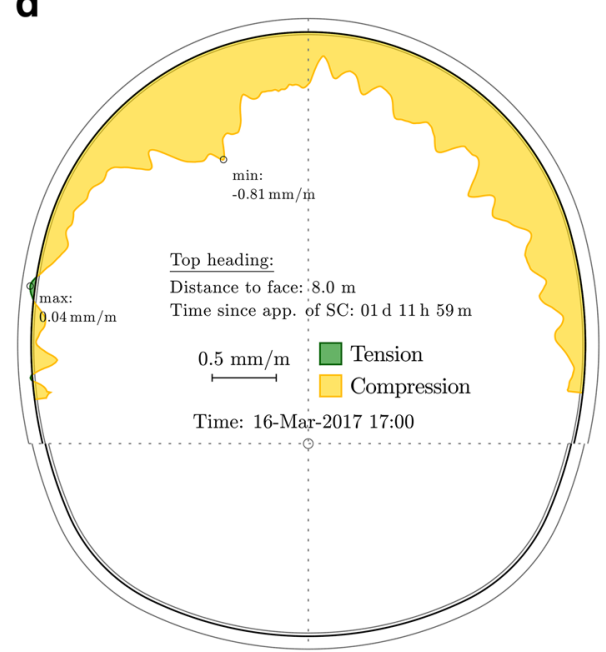

\section{Comparison with Conventional Monitoring Techniques}

To validate the results of the DFOS system, the recorded data is compared with data gained from the installed strain gages and pressure cells (see Sect. 3.2) and with calculation results of the software TunNEL:Suite (Tunnel:Suite 2004) which utilises displacement data of 3D geodetic monitoring targets to approximate the evolution of strain between the individual targets.

\subsection{Comparison DFOS with Strain Recorded by Strain Gages}

To compare the fibre-optic measurement results to those of the vibrating wire sensors, the strain values of the fibre-optic sensing cables in the area of the strain gages are averaged over a length of $30 \mathrm{~cm}$. Figure 10 shows the evolution of changes in strain at the crown (top-heading) of the fibreoptic sensing cables and the strain gages installed in circumferential direction plotted over time.
With a difference of less than $0.2 \mathrm{~mm} / \mathrm{m}$, the data from the DFOS system matches well with the data from the strain gages for both layers. Note that data from the strain gages suggest negative bending moments at the crown, whereas data from the DFOS system suggest positive bending moments. We suppose that this difference is due to variations in the spatial sensor arrangement (especially in longitudinal direction; the strain gages are about $40 \mathrm{~cm}$ in front of the DFOS cables).

\subsection{Comparison DFOS with Pressure Recorded by Pressure Cells}

Next to the strain gages installed at the crown in circumferential direction (Sect. 5.1) a pressure cell with its loading direction parallel (i.e. tangential) to the lining periphery records the pressure acting within the shotcrete lining at this point. The pressure cell extends over both shotcrete layers. Hence, the interaction of both deforming shotcrete layersthe share of each being not quantifiable-determines the pressure recorded by the pressure cell. 

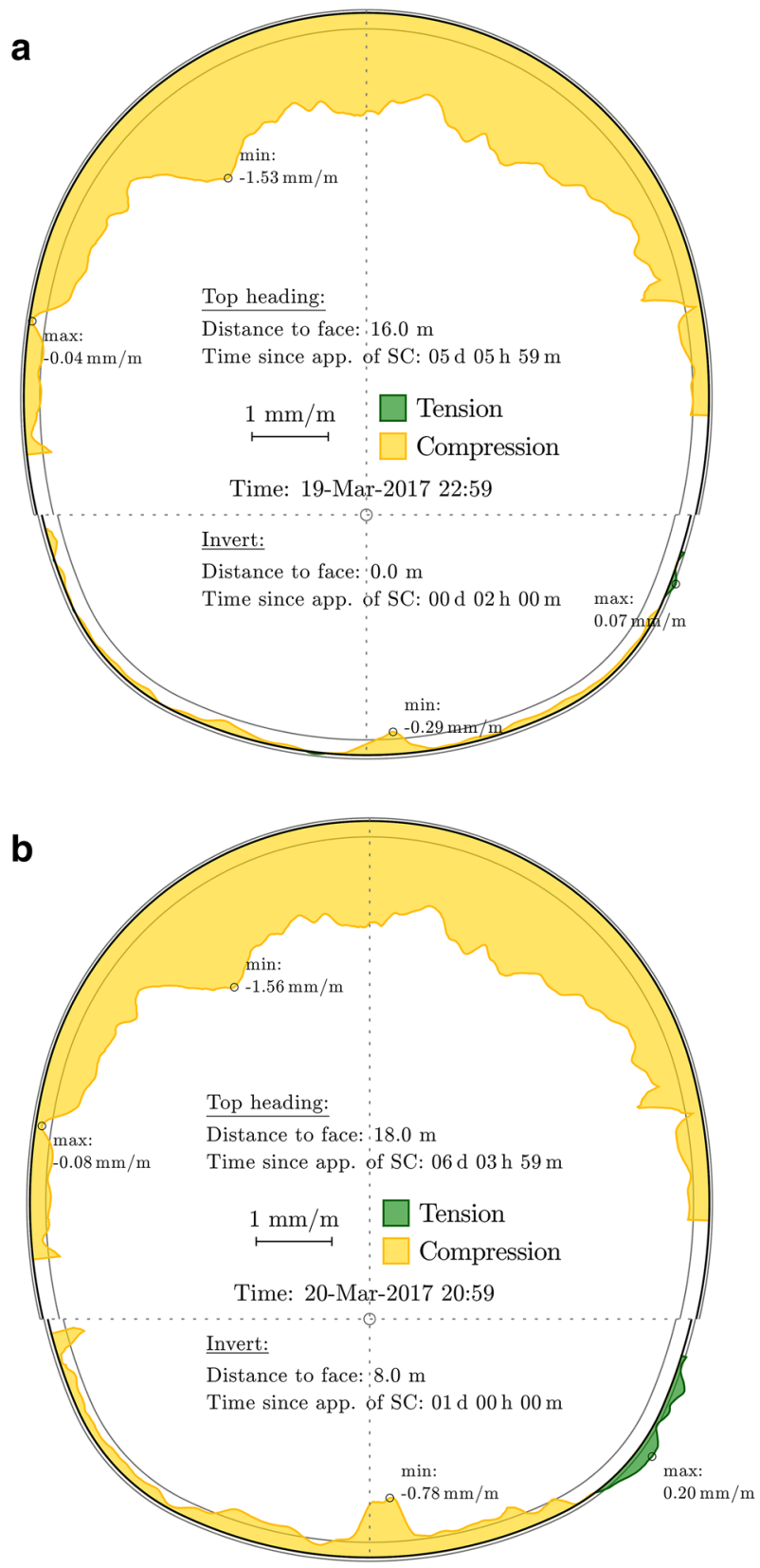

Fig. 9 Circumferential distribution of changes in strain of first layer after support installation at the invert

The green line in Fig. 10 describes the development of the pressure in tangential direction close to the crown during the continuous monitoring period. The shape of the pressure development matches qualitatively well with the development of the changes in strain. With the continuation of the tunnel excavation and with time the pressure increases up to a loading level of approx. $4 \mathrm{MPa}$. However, several distinctive pressure drops can be identified and it seems that they are connected to temperature changes in the tunnel and within the shotcrete lining, respectively.

\subsection{Comparison DFOS with Results of TunNEL:SuITE}

For the comparison of the fibre-optic measurement results with the calculated strain by TunNel:Suite, specific evaluation points (EP) along the circumference of the tunnel are chosen. These points lie between the positions of the geodetic targets as they yield a better representation of the intended outcome in terms of the internal computing mechanism of TunNEL:Suite. Figure 11 shows the evolution of changes in strain near the left shoulder (top-heading) for the cables installed in circumferential direction and the evolution of calculated changes in strain plotted over time. The graph also includes the standard deviation $(1 \sigma)$ of strain derived from the geodetic measurements. For variance propagation the measurement precision of the $3 \mathrm{D}$ geodetic targets is assumed with $1 \mathrm{~mm}$.

The data of the cavity side layer of the DFOS system matches well with the data approximated from the displacements of the monitoring targets. However, the fibre-optic sensing cables at the first rock side layer experience much less compression and the changes in strain strongly differ from the ones calculated by TUNNEL:Suite. A comparison at other points gives a similar picture: the development of the strain increments calculated by TuNNEL:SUITE matches qualitatively with the development of the measured changes in strain of the fibre-optic sensing cables at both layers, but the development of the second cavity side layer is always closer to the calculated one. Table 1 summarises the differences at four representative points along the circumference.

As already mentioned above, deviations might also be a result of the varying spatial sensor position and orientation within the instrumented cross-section. The DFOS sensing cable at the second layer was mounted closer (in the direction of the drive) to the tunnel face of the current excavation round than the first cable layer and is-in the plane of the cross-section-also closer to the geodetic targets. Higher compressional strain arises at the second layer as the excavation continues and differences between the data of the first DFOS layer and strain calculated from the geodetic measurements become visible (Sect. 4.2). Further details about this effect may be found in Monsberger et al. (2018).

\section{Conclusion and Outlook}

This paper shows that implementing a fibre-optic sensing system in a shotcreted tunnel lining has great potential to record strain within the lining with some advantages compared to conventional measuring techniques, like strain gages. The utilisation of a DFOS system at measuring sections can complement 3D geodetic measurements, together providing a full picture of the displacement and deformation of the lining. 
Fig. 10 Comparison of the evolution of changes in strain of the fibre-optic sensing cables in circumferential direction with the strain gages at the crown; primary $y$-axis; positive: tension; negative: compression. Development of tangential pressure near the crown recorded with a pressure cell; secondary $y$-axis

Fig. 11 Comparison of the evolution of changes in strain of the fibre-optic measurements in circumferential direction at the top-heading and the strain calculated by TunNEL:SuITE near the left shoulder. Positive: tension; negative: compression
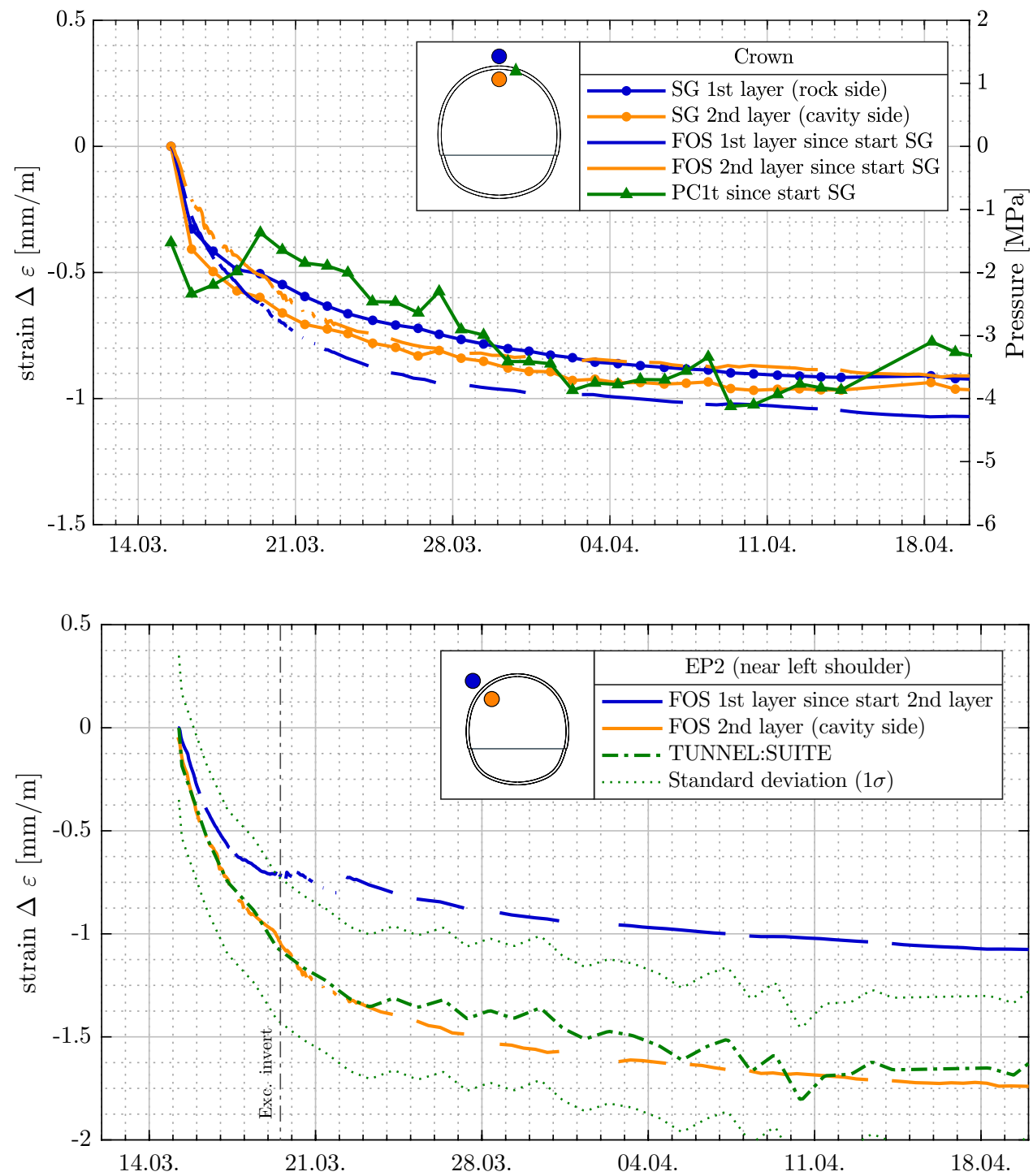

Table 1 Minimum and maximum differences between the recorded changes in strain of the DFOS system and the strain calculated by TuNNEL:SUITE

\begin{tabular}{|c|c|c|c|c|c|c|c|}
\hline \multirow{3}{*}{$\begin{array}{l}\text { Point } \\
\text { EP1 (near left side wall) }\end{array}$} & \multicolumn{3}{|c|}{ Strain diff. min. $(\mathrm{mm} / \mathrm{m})$} & \multicolumn{4}{|c|}{ Strain diff. max. $(\mathrm{mm} / \mathrm{m})$} \\
\hline & First layer & \multicolumn{2}{|c|}{ Second layer } & \multicolumn{2}{|c|}{ First layer } & \multicolumn{2}{|c|}{ Second layer } \\
\hline & 0.16 (1.1 days) & 0.08 & (1.1 days) & 1.05 & (30.1 days) & 0.76 & (30.1 days) \\
\hline EP2 (near left shoulder) & 0.12 (0.1 days) & 0.00 & (0.6 days) & 0.79 & (26.1 days) & 0.20 & (15.3 days) \\
\hline EP3 (near right shoulder) & $0.12 \quad$ (0.1 days) & 0.07 & (0.6 days) & 0.42 & (26.3 days) & 0.38 & (26.3 days) \\
\hline EP4 (near right side wall) & 0.35 (17.3 days) & 0.01 & (17.3 days) & 0.71 & (11.1 days) & 0.36 & (14.1 days) \\
\hline
\end{tabular}

Values in parentheses are days passed since the respective reference measurement
Strain calculated from displacements of monitoring targets are after all 'just' calculated values that can only be as coherent as the theoretical model on which the calculation bases on. Moreover, devices like strain gages, which directly measure the changes in strain within the lining are typically installed only at certain points along the tunnel circumference and can therefore provide local information at these specific positions only. In contrast, the installation of the DFOS system enables recording of strain within the entire lining, meaning also in between the monitoring targets or strain gages. The time required for the system installation is within a reasonable range considering the additional data gain. In the presented case, the installation of the strain gages and pressure cells took more than twice as long as the installation of the fibre-optic instrumentation. Another advantage of the DFOS system is that the cables installed 
operate as sensors and, technically speaking, also as data transfer unit, whereas each conventional strain gage (if not transmitting wireless) requires a data transfer cable.

The used cable type BRUsens strain V3 can withstand the harsh environmental conditions inside the tunnel during its installation process and the given stresses within the lining at the monitoring section under investigation. The structured surface assures optimal bonding with the shotcrete and no indication of slippage could be observed visually during shotcrete application.

The applied temporary point-wise fixation method with cable ties offers a quick and adequate possibility to mount the individual fibre-optic cable lines to the wire mesh. This can be done by the workers on site, which confirms the general applicability of this system under the rather rough conditions of a tunnelling construction site. The fixation is robust enough to sustain the application of shotcrete under full spraying performance. The final continuous bonding with the shotcrete is given by the structured surface of the cable. The protective tube used containing the cable for temperature compensation has shown a good performance as the smooth surface inside provides minor frictional resistance.

Yet, the biggest drawbacks of DFOS systems are their present costs, which are currently way higher than the mentioned conventional monitoring devices. However, developments of commercial DFOS systems are still in progress, which will possibly lead to cost savings in the near future.

The results of the fibre-optic measurements highlight the overall, real-time deformation of the tunnel lining, which enables a correlation with the geological situation documented at the respective chainage.

The gained data can also be used to back-calculate the stress distribution of the lining from the measured strain. Different approaches are known from the literature to do so, e.g. the improved rate of flow method proposed by Aldrian (1991) [based on the rate of flow method proposed by England and Illston (1965)] or more sophisticated models like the shotcrete model presented by Schädlich and Schweiger (2014) or the thermochemomechanical material model proposed by Hellmich (1999).

For future applications it would be conceivable to measure more than one cross-section at once by simply connecting them via supply cables to a fibre-optic sensing chain. In addition, certain preparations for follow-up measurements of the installed fibre-optic sensing cables even after the construction of the inner lining would be reasonable to assess the long-term structural integrity of the outer lining and gain better understanding of the processes taking place after construction.

Acknowledgements Open access funding provided by Graz University of Technology. The authors thank the Austrian Federal Railways ÖBB, in particular Mr. Oliver Kai Wagner and Mr. Tobias Schachinger, for the opportunity to conduct this research project. Thanks to the workers of the construction joint venture SBT 1.1 Tunnel Gloggnitz-Implenia Österreich, HOCHTIEF Infrastructure Austria, Thyssen Schachtbau and especially to Mr. Gerold Lenz, former head of the Geotechnical Team Underground (GTU) on site.

Open Access This article is distributed under the terms of the Creative Commons Attribution 4.0 International License (http://creativeco mmons.org/licenses/by/4.0/), which permits unrestricted use, distribution, and reproduction in any medium, provided you give appropriate credit to the original author(s) and the source, provide a link to the Creative Commons license, and indicate if changes were made.

\section{References}

Aldrian W (1991) Beitrag zum Materialverhalten von früh belastetem Spritzbeton. PhD thesis, Montanuniversität Leoben, Austria

Brugg Kabel AG (2012) Datasheet: BRUsens strain V3. Version: 2012/09/12 Rev. 02 TH, Brugg, Switzerland

de Battista N, Elshafie M, Soga K, Williamson M, Hazelden G, Hsu YS (2015) Strain monitoring using embedded distributed fibre optic sensors in a sprayed concrete tunnel lining during the excavation of cross-passages. In: Proceedings of the 7th international conference on structural health monitoring of intelligent infrastructure

Döring H, Habel W, Lienhart W, Schwarz W (2016) Faseroptische Messverfahren. In: Freeden W, Rummel R (eds) Handbuch der Geodäsie. Springer, Berlin, pp 1-48

England GL, Illston JM (1965) Methods of computing stress in concrete from a history of measured strain. Civil Engineering and Public Works Review, 60, Parts 1, 2 and 3, April, May and June 1965, pp 513-17, 692-694, 846-847

Gehwolf P, Monsberger C, Barwart S, Weninghofer R, Galler R, Lienhart W, Haberler-Weber M, Moritz B, Barwart C, Lange A (2016) Deformation measurements of tunnel segments at a newly developed test rig. Geomech Tunnell 9(3):180-187

Hellmich C (1999) Shotcrete as part of the New Austrian tunneling method: from thermochemomechanical material modeling to structural analysis and safety assessment of tunnels. $\mathrm{PhD}$ thesis, Institute for Strength of Materials, Vienna University of Technology, Austria

Henzinger M, Schachinger T, Lienhart W, Buchmayer F, Weilinger W, Stefaner R, Haberler-Weber M, Haller E-M, Steiner M, Schubert W (2018) Fibre-optic supported measurement methods for monitoring rock pressure. Geomech Tunnell 11(3):251-263

Kreger ST, Gifford DK, Froggatt ME, Soller BJ, Wolfe MS (2006) High resolution distributed strain or temperature measurements in single-and multi-mode fiber using swept-wavelength interferometry. In: Proceedings of optical fiber sensors, ThE42, Cancun, Mexico

Luna Innovations Inc. (2014) Datasheet: optical backscatter reflectometer (Model OBR 4600), LTOBR4600 REV.004 02/13/2014, Roanoke, USA

Monsberger C, Lienhart W (2017) In-situ deformation monitoring of tunnel segments using high-resolution distributed fibre optic sensing. In: Proceedings of the 8th international conference on structural health monitoring (SHMII-8), Brisbane, Australia

Monsberger C, Woschitz H, Hayden M (2016) Deformation measurement of a driven pile using distributed fiber-optic sensing. J Appl Geod 10:61-69

Monsberger C, Woschitz H, Lienhart W, Racansky V (2017) Performance assessment of geotechnical structural elements using distributed fiber optic sensing. In: Proceedings of SPIE 10168, sensors and smart structures technologies for civil, mechanical, and aerospace systems 
Monsberger C, Lienhart W, Kluckner A, Wagner L, Schubert W (2018) Continuous strain measurements in a shotcrete tunnel lining using distributed fibre optic sensing. In: Proceedings of the 9th European workshop on structural health monitoring, Manchester, UK

Moser F, Lienhart W, Woschitz H, Schuller H (2016) Long-term monitoring of reinforced earth structures using distributed fiber optic sensing. J Civ Struct Health Monit 6(3):321-327

Schädlich B, Schweiger HF (2014) A new constitutive model for shotcrete. In: Proceedings of the 8th European conference on numerical methods in geotechnical engineering, Delft, The Netherlands, 18-20 June 2014, CRC Press Taylor \& Francis: Leiden, The Netherlands, pp 103-108

Schubert W, Schubert P (1993) Tunnels in squeezing rock: Failure phenomena and counteractions. In: Proceedings of the international symposium on assessment and prevention of failure phenomena in rock engineering, Istanbul, Turkey, pp 479-484
Schuller H, Riepler F, Schachinger T (2014) Preliminary works for the new Semmering Base Tunnel-geotechnical monitoring of slope stabilization measures. Geomech Tunnell 7(4):339-352

Tunnel:Suite (2004) Gruppe Tunnel:Monitor, iC consulenten Ziviltechniker GesmbH, IGT Geotechnik und Tunnelbau Ziviltechniker G.m.b.H., 3G Gruppe Geotechnik Graz ZT GmbH

Wagner L (2017) Concept and realisation of a distributed fibre-optic sensing system for direct and continuous strain measurement in a shotcrete lining. Master's thesis, Institute of Rock Mechanics and Tunnelling, Graz University of Technology, Austria

Publisher's Note Springer Nature remains neutral with regard to jurisdictional claims in published maps and institutional affiliations. 